\title{
Amniotic band syndrome and/or limb body wall complex: split or lump
}

\author{
This article was published in the following Dove Press journal: \\ The Application of Clinical Genetics \\ 3 February 2010 \\ Number of times this article has been viewed
}

\section{Ashutosh Halder \\ Department of Reproductive Biology, All India Institute of Medical Sciences, New Delhi, India}

\begin{abstract}
Six cases of amniotic band syndrome/limb body wall complex were studied in respect to clinicopathologic characteristics. The diagnosis was based on two out of three of the following manifestations: cranio facial clefts; limb body wall defects and amniotic band attachment. Four cases were stillborn and associated with internal defects, including central nervous system. Two cases had facial and limb defects and were live born (3-5 years old at examination). Phenotypic features of the stillborn cases were craniofacial clefting, thoracoabdominoschisis, amputation, ring constriction, amniotic band adhesion, placental adhesions, and internal malformations. Histology of bands revealed fibroconnective tissue as well as flattened epithelial cells together with neuroectodermal elements. Umbilical cord section revealed an abnormal number of vessels. When analyzing the observed data in relation to their etiology, it was found that amniotic disruption, vascular disruption or genetic disruption could explain the amniotic band syndrome/ limb body wall complexes, alone or in combinations. A brief review of literature in search of pathogenesis is offered along with an etiopathogenetic model.
\end{abstract}

Keywords: amniotic band syndrome, limb body wall complex and pathogenesis

\section{Introduction}

Amniotic band syndrome (ABS) and/or limb body wall complex (LBWC) is considered to be caused by rupture of the amnion with secondary effects on the fetus producing malformation due to interruption of normal morphogenesis, deformation due to distortion of established structures and disruption of structures already formed. ${ }^{1,2}$ It may be associated with loss of amniotic fluid, producing secondary effects due to oligo-hydramnios. ${ }^{3}$ It is seen in 1 in 70 spontaneous abortions. ${ }^{4,5}$ In newborns, it has been estimated to occur 1 in 1300-2000 births. ${ }^{6,7}$ The syndrome is under diagnosed and its presentation is so variable that no two cases are exactly alike.

Pathogenesis of this defect is probably heterogeneous. Mechanisms invoked have included germ disc disruption, ${ }^{8-11}$ genetic disruption, ${ }^{12,13}$ vascular disruption ${ }^{14-16}$ and amniotic disruption. ${ }^{1,2,17}$ Here we analyze six cases of ABS/LBWC with special consideration on pathogenenesis.

\section{Clinical reports}

Four stillborn fetuses with multiple congenital malformations were referred to the Department of Medical Genetics, Sanjay Gandhi Post Graduate Institute of Medical Sciences (SGPGIMS), Lucknow, for evaluation and all autopsies were undertaken by the author. Two children with facial and limb malformation (post-operated) were referred to the outpatient department of Medical Genetics, SGPGIMS for diagnosis
Corshotosh Halder New Delhi I 10029, India

Tel $+9|-||-265942|$ I

Fax +9I-I I-26588663

Email ashutoshhalder@gmail.com 
and counseling, and were evaluated by the author. Information on major characteristics of the cases are presented in Table 1.

\section{Case I}

Case 1, a stillborn fetus, was the result of the first pregnancy of a mother aged 21 years. Except for hyperemesis in first trimester (treated with doxinate, an antiemetic) the pregnancy was uneventful until 32 weeks gestation when the fetal membranes ruptured spontaneously. An ultrasound examination revealed fetal death and multiple congenital malformations; so the pregnancy was terminated. There was no history of congenital malformation in family. Routine antenatal investigations were normal.

The fetus was female, weighed $498 \mathrm{~g}$ and had multiple congenital malformations (Figure 1a). Anencephaly was present with meninges attached to fetal membranes. The left eye was absent and the right was small with deformed eyelids. The nose was deformed with only one nostril and the ears were also deformed. There were lateral clefts of the angles of the mouth. There was a continuous defect of the thoracic and abdominal wall (thoracoabdominoschisis; Figure 1b). The margins of the defect were smooth (Figure 1b, arrow). The thoracoabdominal organs were situated outside the body cavities. The apex of heart was turned upwards and was attached to an unspecified tissue (histologic analysis revealed this to be glial tissue) on upper part of chest. Both lungs were partially lobulated and severely hypoplastic (combined weight $8 \mathrm{~g}$ ). The diaphragm was inverted. The abdominal organs showed several anomalies. The liver was unlobulated, globular and congested (Figure 1f). There was agenesis of the gallbladder, right ovary, right uterine tube and right cornu of uterus (right mullerian duct and right kidney). The uterus was unicornuate and there was no anus. Multiple skin tags were seen between the fetus and the placenta. The limb defects were limited to a rudimentary right upper limb, rocker bottom feet, short right first toe and clubfoot on the right side (Figure 1c). The amniotic band was adherent on the left dorsum of the foot (Figure 1d). The fetal trunk was hyperextended with both scoliosis and a twist (Figure 1e).

The placenta weighed $350 \mathrm{~g}$ and was attached to the buttock, back and meninges (Figure 1a). The umbilical cord was short (6 cm effective length, $17 \mathrm{~cm}$ total length) and lusterless but without any knot, twist or constriction. The number of vessels in cord was 3 to 10 , of which 2 were abnormal.

Histologically the placenta revealed discrete vascular chorionic villi with dilated vascular channels. The liver, spleen and adrenals were markedly congested and the kidney showed extensive intimal proliferation of hilar vessels. The rudimentary limb was contained cartilaginous tissue covered with adipo-fibro-connective tissue and skin. It was devoid of osteoid tissue and muscles (Figure 1g). The membrane which was attached to the meninges showed flattened epithelial cells enclosing a pseudoglandular structure and displayed in places, neuroectodermal elements and ganglia.

\section{Case 2}

Case 2 was also a stillborn fetus although this time the mother was 25 years of age. The mother had a previous full term cesarean section delivery of a female child with neural tube defect (NTD; lumbo-sacral meningomyelocele with hydrocephalus). This pregnancy was uneventful until 26 weeks gestation when the fetal membranes ruptured spontaneously. An ultrasound examination revealed fetal death along with malformations and so the pregnancy was terminated. Maternal routine antenatal investigations and later (postnatally) TORCH (toxoplasmosis, other, rubella virus, cytomegalovirus, and herpes simplex viruses), GTT (glucose tolerance test) and chromosomal analysis was normal.

Table I Summary of major characteristics of the cases

\begin{tabular}{|c|c|c|c|c|c|c|}
\hline Manifestations & Case I & Case 2 & Case 3 & Case 4 & Case 5 & Case 6 \\
\hline Facial clefts & + & + & + & + & + & + \\
\hline Bands/rings/constrictions & + & + & + & + & + & + \\
\hline Digital amputation & + & + & + & + & + & + \\
\hline Cranial/CNS defect & + & + & + & + & + +- & - \\
\hline Limb deficiency/amputation & + & + & - & + & - & - \\
\hline Internal malformations & + & + & + & + & - & - \\
\hline Body wall defects & + & - & + & + & - & - \\
\hline Short cord & + & $\mathrm{NI}$ & + & + & $\mathrm{NI}$ & $\mathrm{NI}$ \\
\hline
\end{tabular}

Abbreviations: +, present in the case; -, absent in the case; $\mathrm{NI}$, no information. 



Figure I Photographs of case I, a stillborn fetus.

Notes: A: fetus with placental attachment (with buttock and back) and facial clefting (bottom facing); B: thorachoabdominoschisis (small arrow is showing smooth margin of body wall defect) with upward direction of apex of heart (long arrow), C: rocker bottom foot (small arrow), constriction ring (long arrow) and overall body twist; D: amniotic band attachment with soft tissue disruption in dorsum, E: fetal necrogram showing acrania, scoliosis and twisting of trunk and limbs (compression effect); F: globular liver without gall bladder, G: photomicrograph of rudimentary limb showing devoid of osteoid tissue.

The female fetus weighed $550 \mathrm{~g}$ and had multiple congenital malformations. The head was extremely dolicocephalic with deficiency of scalp over the occiput, measuring $4 \mathrm{~cm}$ in diameter (Figures 2a,f). From the delivery notes it was found that one pole of placenta was attached to occiput. Cleft lip and cleft palate was observed (Figure 2b). The left upper limb was amputated at mid-forearm with edema, necrosis and hemorrhage around the proximal stump (Figure 2c,e). The left leg had a constriction ring. Other abnormalities were deep furrows on soles and a wide gap between first and second toes (Figure 2d). The thoracic organs showed several anomalies including pulmonary hypoplasia and cardiac malformation (tetralogy of Fallot). No anomalies were noted in abdominal organs.

\section{Case 3 and 4}

Both these cases were stillborn fetuses and resulted from second pregnancies. The two mothers aged 22 and 24 years both had spontaneous abortions, during the first trimester of their first pregnancies. Their second pregnancies were uneventful until 20 weeks and 28 weeks gestation when an ultrasound examination revealed multiple congenital malformations. As a result the both pregnancies were terminated. There was no history of congenital malformation in families and routine antenatal investigations were normal.

The male fetus weighed $350 \mathrm{~g}$ and a female $495 \mathrm{~g}$ and both had multiple congenital malformations. The placenta was attached with head and face resulting in severe disruptive effects of the face (clefting) and head (anencephaly) along with thoracoabdominoschisis (Figures 3a,b,c and 4a,b). The left thigh had a constriction ring (Figures 3a,c). Thoracic and abdominal organs showed several anomalies including generalized hypoplasia. The umbilical cords were small with abnormal attachments, on fetal side and placentae were attached with head and face in both the fetuses.

\section{Case 5 and 6}

These were a male (aged 4 years) and female child (aged 3 years) born to a para one mother aged 21 and a para three mother aged 25 years old. Both mothers had no antenatal care 


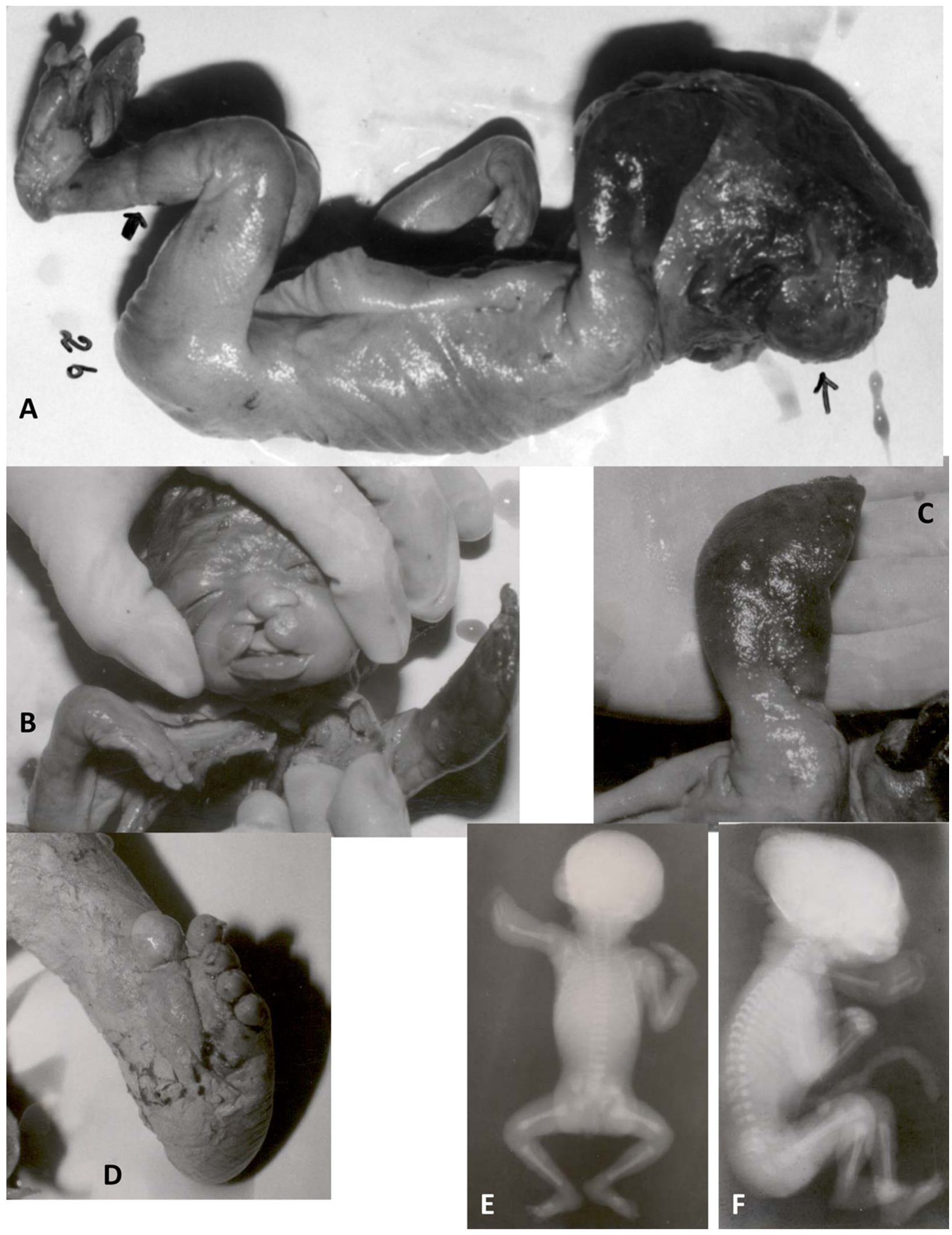

Figure 2 Photographs of case 2, a stillborn fetus.

Notes: A: dolicocephalic head with scalp disruption at occiput (long narrow arrow) due to placental attachment (post necropsy) and constriction ring (short arrow); B: facial clefting; C: amputated upper limb (with signs of inflammation, hemorrhage and necrosis); D: groove (furrow) on sole of foot, E and F: fetal necrogram showing amputated upper limb at mid forearm (E) and dolicocephalic head (F). 

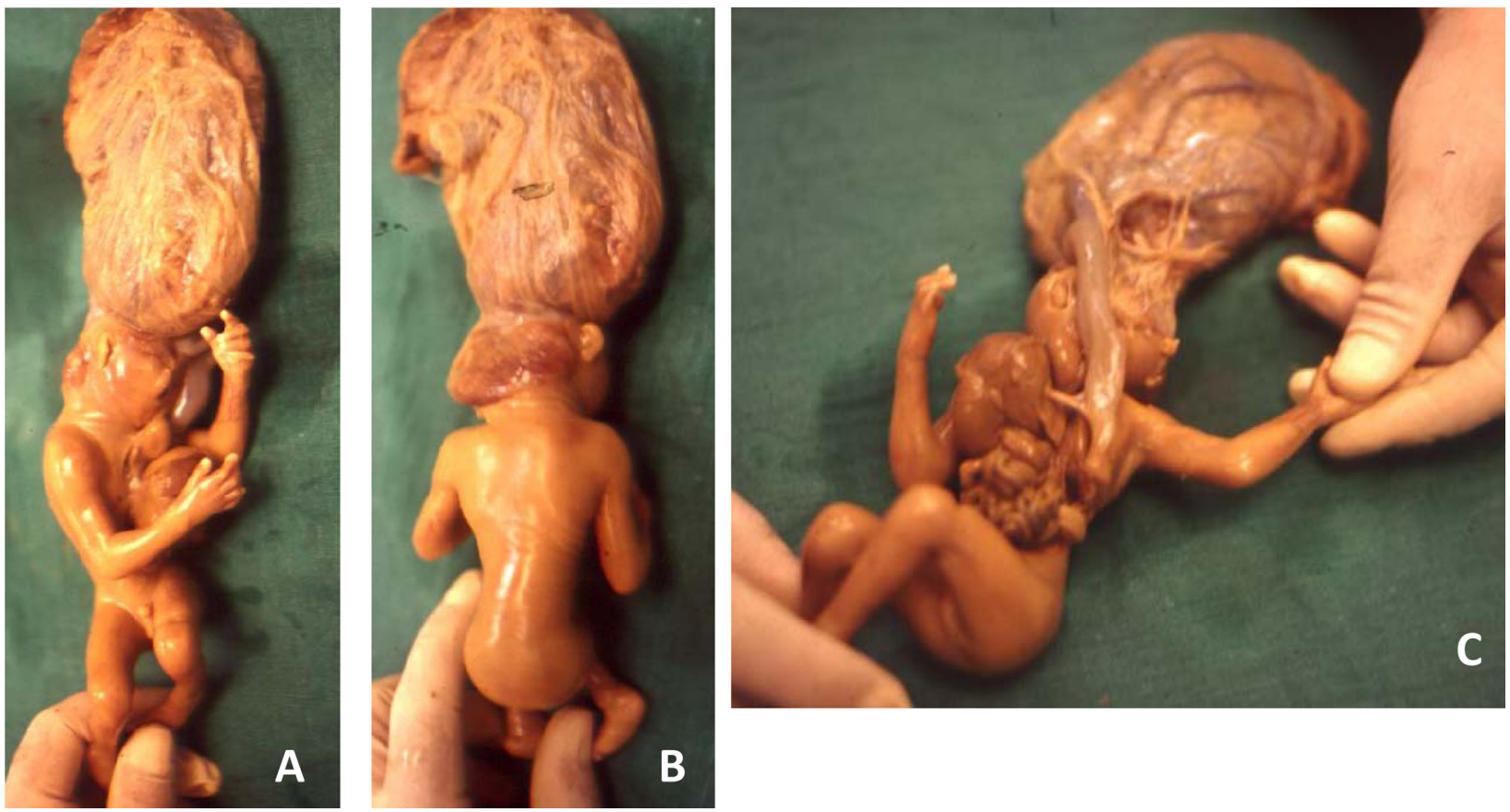

Figure 3 Photographs of case 3, a stillborn male fetus.

Notes: A: placental attachment with head (lateral view); B: anencephaly with placental attachment (posterior view); C: thoracoabdominoschisis, facial disruption, constriction ring (left lower thigh) and short umbilical cord.

and no history of drug intake during pregnancy. The family history was noncontributory. The children were born at term with average birth weight and multiple congenital defects. Both had a cleft lip and cleft palate (this had been repaired in one). Case 5 had broad and angulated nose, down turned angles of mouth and mild facial asymmetry (Figure 5a). Reduction anomaly of digits with proximal syndactyly (Figure 5b) and constriction bands was observed in both the
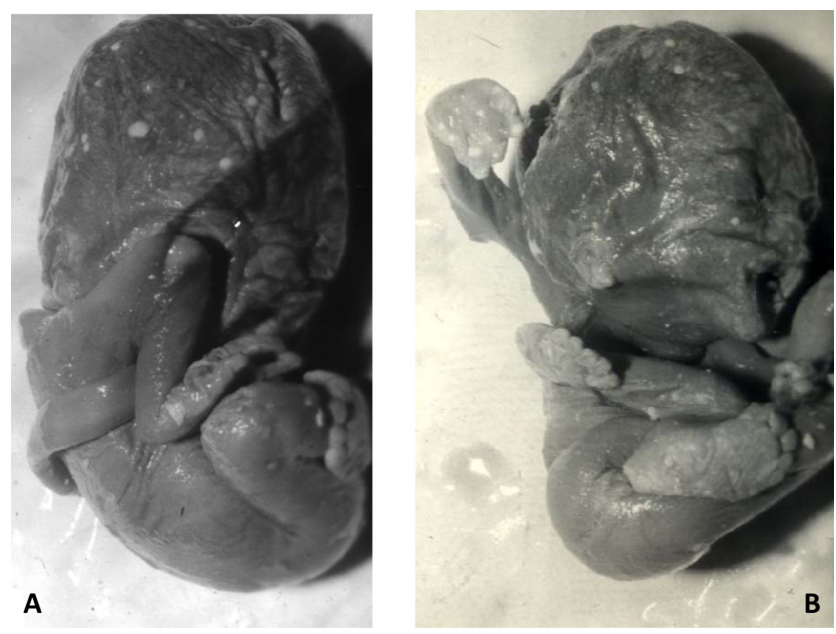

Figure 4 Photographs of case 4 , a stillborn female fetus.

Notes: A (lateral view) and B (front view): placental attachment (with head, neck and face) and short umbilical cord. cases. Limb constriction anomalies of case 5 (Figure 5c) were more severe than case 6 . In addition case five had bone deficiency on frontal eminence and large fibrosed area over left shoulder.

\section{Discussion}

The malformations in these six cases examined closely resemble descriptions of early amnion rupture sequence, ${ }^{18}$ amniotic band syndrome, ${ }^{1}$ limb body wall malformation complex ${ }^{15}$ and fetal disruption complex. ${ }^{19}$ Single phenotype (resulting from placenta/membrane attachment with fetus/ embryo followed by effects due to fetal movement that result in pulling, disruption, and entanglement of fetal parts, with/or without oligohydramnios [compression effect as well as pulmonary hypoplasia]) with different terminology by different investigators, indicates only etiopathologic heterogeneity. This review of six cases suggests that such abnormalities are more consistent with a continuum of severity and body system involvement (case 6 least affected and case 1 maximally affected), rather than different diagnostic clusters.

The earliest case was described by Portal (1685). ${ }^{20}$ Despite recognition for more than 300 years, fetal disruption complex is a constellation of congenital malformation that lacks precise definition and a satisfactory pathogenetic explanation. It is characterized by fetal anomalies caused by various 


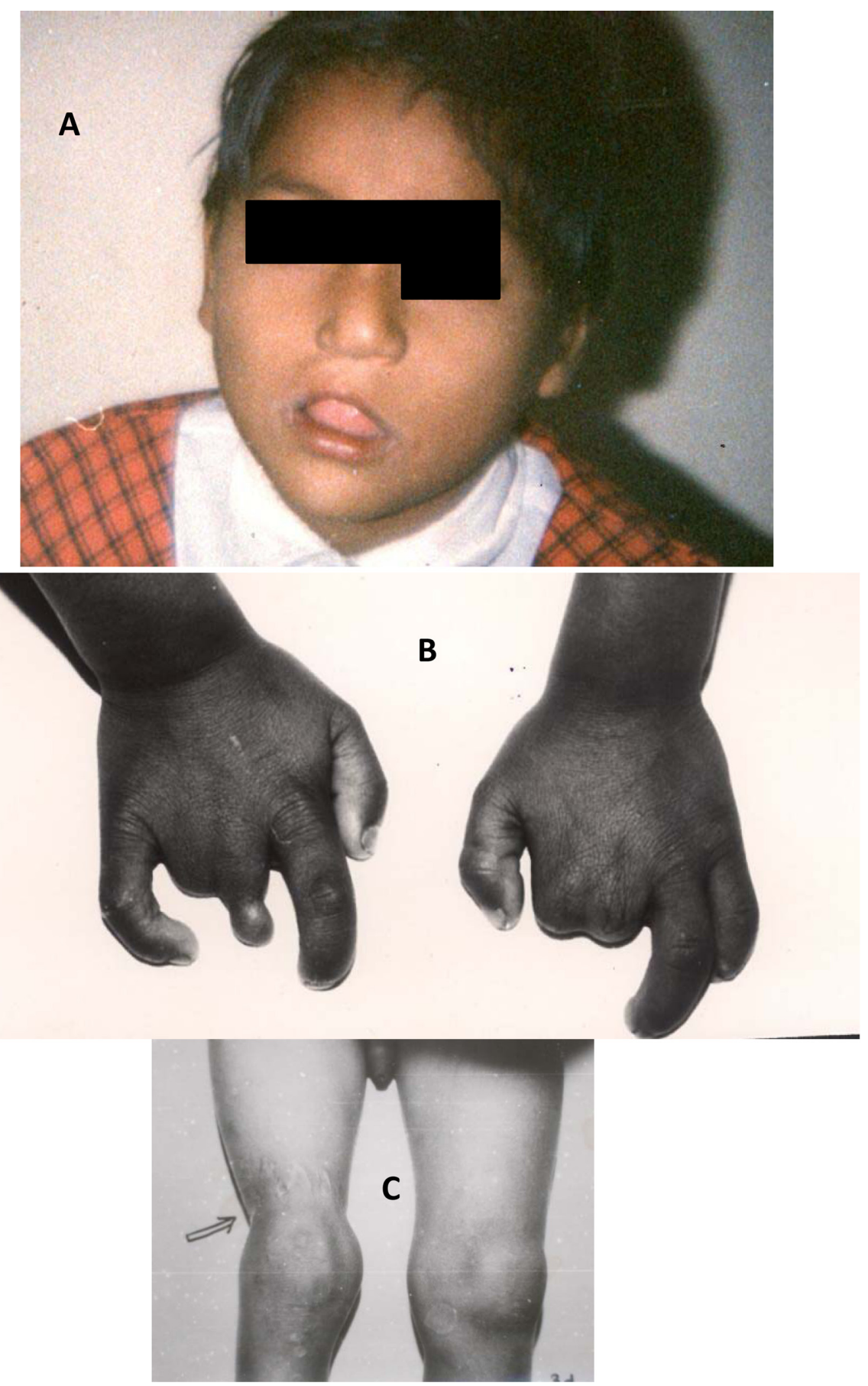

Figure 5 Photographs of Case 5, a male child.

Notes: A: facial view showing evidence of facial cleft and deformed nose (post surgical repair); B: digit amputation and syndactyly; C: constriction ring (arrow)

mechanisms including aberrant embryonic morphogenesis, fetal/embryonal vascular compromise, mechanical deformations and secondary disruption of normally developed structures. Occurrence of amniotic bands would appear to be a requirement for the diagnosis; however, the presence of fetal malformation in a non-embryogenic distribution can allow the diagnosis even in the absence of bands. A critical analysis of these cases calls for reevaluation of pathogenesis of the cited theories.

\section{Amniotic disruption (exogenous) theory}

Amniotic band theory of Torpin $(1965)^{1}$ supports the exogenous nature of defects that result from rupture of the amniotic sac. He supposed that once the amnion is ruptured the fetus lies 
outside amniotic cavity. From the chorionic side of amnion, mesodermal bands emanate which entrap various parts of the fetus and disturb normal development. Early rupture would lead to more severe malformations (eg, craniofacial and visceral) whereas later rupture would lead to milder forms. Oligohydramnios may aggravate the deformity through compression. ${ }^{17}$ Higginbottom in 1979 described 79 patients that supported the band theory resulting from observations of unusual facial clefts, which were not along the planes of facial closure. ${ }^{2}$ Also in support of the band theory Bhat, in his case report, described the presence of a well formed amputated distal portion of one leg and fibrous bands coiling around the fingers of the amputated segment. ${ }^{21}$ Many investigators have questioned this theory. ${ }^{9,15,22}$ Van Allen noted bands only in $40 \%$ of cases and internal defects in $95 \%$ of cases; features that could not be attributed to amniotic bands. ${ }^{15}$ Herva has refuted this theory on the basis of the high prevalence of internal anomalies. ${ }^{9}$ Further criticism of the amniotic disruption theory is derived from the reports of Yang who described that antenatal amniotic rupture results in extra-amniotic pregnancy that displays no evidence of amniotic bands. ${ }^{22}$ Of the cases described here, all show some evidence for amniotic band and/or placental attachment to the fetus although not enough to explain all the malformations. Anomalies not explainable by the amniotic disruption theory are internal malformations - tetralogy of Fallot (TOF; case 1), rudimentary upper limb (case 1), abnormal number and morphology of umbilical vessels (case 1) and short great toe (case 1).

\section{Vascular disruption theory (VDT)}

VDT was proposed by van Allen and implies that various congenital malformations may generally result from vascular disruption. ${ }^{14}$ Vascular disruption is described as events that negatively influence normal embryonic blood supply during embryogenesis, thereby interrupting normal morphogenesis or destroying previously existing structures. VDT is supported by experimental animal studies. ${ }^{23,24}$ Puncturing the amniotic cavity or ligating umbilical blood vessels has produced LBW complex. In amnion puncture experiments, up to one third of the total amniotic fluid was withdrawn, thereby greatly influencing placenta-fetal circulation. Many investigators have also questioned this theory. ${ }^{25,26}$ In human situations no immediate loss of amniotic fluid is expected after rupture of the amniotic membrane during early pregnancy (because the chorion is usually spared) so no such vascular change is expected. However, when adhesion and bands form this factor occurs and plays a role in disruption. Anomalies not explainable with VDT are anencephaly, absent orbit (one sided), oblique facial cleft, deformed nose (single nostril), rocker bottom feet, pulmonary hypoplasia, unlobulated liver, abnormal number of umbilical vessels, cardiac defect (TOF), skin tag and facial dysmorphism. Hence this pathogenetic mechanism cannot explain all the anomalies described in several of the cases in this series.

\section{Embryonic dysplasia theory (endogenous)}

This theory was presented by Streeter in 1930 and he suggested that fetal disruptions resulted from imperfect histogenesis. ${ }^{8}$ Streeter's theory was based on a thorough macroscopic and microscopic examination of constrictions in 16 cases. He concluded that structures that have been mistaken for amniotic bands are residua of localized area of defective tissue. McKenzie supported this theory and further suggested that defective tissue at the site of constrictions reflects an abnormal distribution of areas of cell death, a physiological feature in normal embryogenesis (programmed cell death). ${ }^{27}$ Ectodermal placodes are involved in the formation of many organs and structures including the neural tube, nose, branchial arches, ventral body wall and limbs. Malformation results when ectodermal placodes do not function correctly. A malfunction of body wall placodes will lead to thoracoabdominoschisis or body wall dysplasia. Malfunction of limb bud placodes may result in the reduction limb anomalies and constriction. Likewise the involvement of rostral placodes results in neural tube defects and facial cleft. Some of these malformations were observed in our cases and correspond to malfunction of ectodermal placodes - rudimentary limbs, thoracoabdominoschisis, internal organ malformations. Internal malformations observed in our cases also reflect mesodermal development defects. In case 1 unilateral agenesis of ovary and Mullerian ducts (fallopian tube and one cornu of the uterus) along with hypoplasia of the kidney (same side) and ipsilateral rudimentary upper limb suggests developmental failure of intermediate mesoderm. Lash reported the intimate development of mesonephros (genitourinary) and upper limb bud cartilage that were evident in case 1, where same sided upper limb and genitourinary defects existed. ${ }^{28}$ However, this theory cannot explain all the observed malformations in our cases - unusual facial cleft, craniofacial defect, amputation.

However the literature also cites familial cases of amniotic band syndrome, families in which defects are inherited as an autosomal dominant trait. ${ }^{22,29-32}$ Furthermore reports of temporal-geographic clustering implicates an environmental teratogen. ${ }^{33,34}$ Lockwood described 14 cases of amniotic band syndrome associated with twin pregnancies 


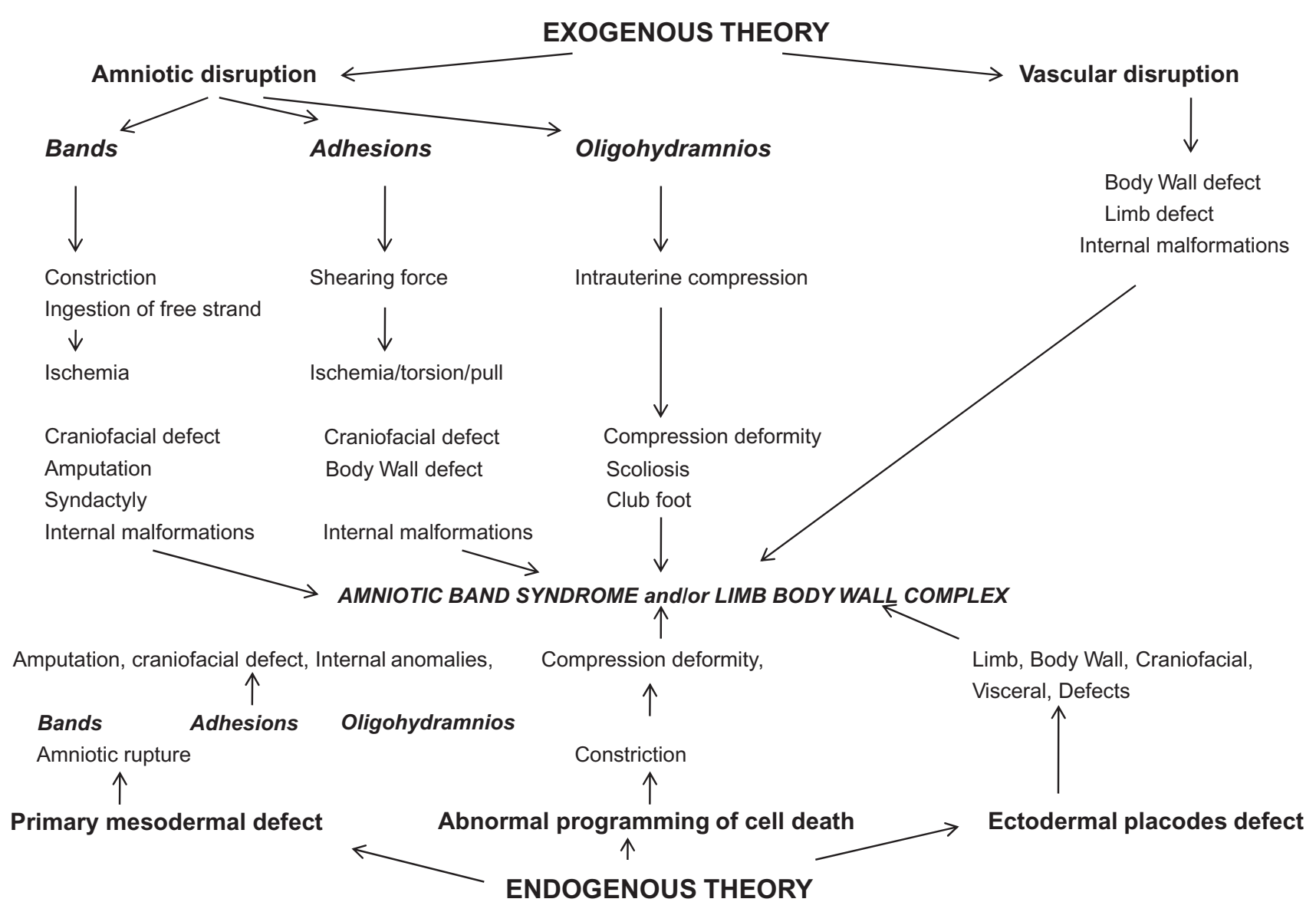

Figure 6 Pathways of Limb Body Wall Complex/Amniotic Band Syndrome arising from different primary events (modified model of Luebke and colleagues ${ }^{19}$ ).

(mostly in monozygotic). ${ }^{35}$ This finding supports the hypothesis that the disorder is a consequence of teratogenic insult because monozygous twining is theorized to be the result of teratogenic stimuli. ${ }^{35}$

Russo and colleagues have tried to divide this entity into two distinct phenotypes, the first consisting of craniofacial defects with amniotic bands and the second lacking craniofacial defects, though associated with urogenital anomalies, anal atresia, abdominal placental attachment and persistance of the extra embryonic coelome. ${ }^{36}$ However, case one in this report had manifestations of both phenotypes described by Russo et al and suggests that it may not be possible to divide this condition clearly on a phenotypic basis. Case 1 had findings of both craniofacial defects and amniotic bands (attached to left foot). These can only be accounted for by early amnion rupture sequence, ${ }^{1}$ embryonic vascular disruption ${ }^{15}$ and embryonic dysplasia ${ }^{8,37}$ together. On the basis of these cases one can conclude that it may not always be possible to split the entity of LBWC either phenotypically, morphologically or etiopathologically.
Analysis of our cases indicates that amniotic band syndrome may not primarily be the consequence of amniotic or vascular disruption but rather the result of multifactorial processes responsible for the developmental malformations and fetal ecto-mesodermal disruption leading to amniotic rupture and vascular compromise. The distribution of characteristics with these cases supports the idea of a continuum of characteristics of variable severity rather than separate entities. It appears that $\mathrm{ABS} / \mathrm{LBWC}$ is a syndrome of etiopathogenetic heterogeneity where the above modes of pathogenesis, in combination, produces some or all of the clinical picture of ABS/LBWC (Figure 6; modified model of Luebke ${ }^{19}$ ).

\section{Acknowledgments}

The author wishes to thank the Department of Medical Genetics, Pathology and Radiology, SGPGIMS, Lucknow for work-up of cases, including autopsy.

\section{Consent}

Consent was given, by the parents of these cases, for both the autopsy and the taking of clinical photographs. This work 
was done between 1991 and 2001 while the author was at SGPGIMS.

\section{Disclosure}

The author reports no potential conflicts of interest.

\section{References}

1. Torpin R. Amniochorionic mesoblastic fibrous strings and amnionic bands: associated constricting fetal malformations or fetal death. Am J Obstet Gynecol. 1965;91:65-75.

2. Higginbottom MC, Jones KL, Hall BD, Smith DW. The amniotic band disruption complex: timing of amniotic rupture and variable spectra of consequent defects. J Pediatr. 1979;95:544-549.

3. Torpin R. Fetal malformations. In: Amniotic Bands. 1st Edn. Springfield, Illinois: WB Saunders Co; 1968. p. 130-137.

4. Byrne J, Blanc WA, Baker D. Amniotic band syndrome in early fetal life. Birth Defects Orig Artic Ser. 1982;18(3B):43-58.

5. Kalousek DK, Bamforth S. Amnion rupture sequence in previable fetuses. Am J Med Genet. 1988;31:63-73.

6. Ossipoff V, Hall BD. Etiologic factors in the amniotic band syndrome: a study of 24 patients. Birth Defects Orig Artic Ser. 1977;13(3D):117-132.

7. Froster UG, Baird PA. Amniotic band sequence and limb defects: data from a population-based study. Am J Med Genet. 1993;46:497-500.

8. Streeter GL. Focal deficiency in fetal tissues and their relation to intrauterine amputation. Contrib Embryol. 1930;33:41.

9. Herva R, Karkinen-Jaaskelainen M. Amniotic adhesion malformation syndrome: fetal and placental pathology. Teratology. 1984;29(1):11-19.

10. Bamforth JS. Amniotic band sequence: Streeter's hypothesis reexamined. Am J Med Genet. 1992;44:280-287.

11. Hartwig NG, Vermeij-Keers C, De Vries HE, Kagie M, Kragt H. Limb body wall malformation complex: an embryologic etiology? Hum Pathol. 1989;20:1071-1077.

12. Donnai D, Winter RM. Disorganisation: a model for early amnion rupture? J Med Genet. 1989;26:421-425.

13. Hunter AGW, Carpenter BF. Implications of malformations not due to amniotic bands in the amniotic band sequence. Am J Med Genet. 1986;24:691-700.

14. Van allen MI. Fetal vascular disruptions: mechanisms and some resulting birth defects. Paediatric Annzales. 1981;10:219-233.

15. Van Allen MI, Curry C, Gallagher I. Limb body wall complex: Pathogenesis. Am J Med Genet. 1987;28:529-548.

16. Van Allen MI. Structural anomalies resulting from vascular disruption. Pediatr Clin North Am. 1992;39:255-277.

17. Miller ME, Graham JM Jr, Higginbottom MC, Smith DW. Compressionrelated defects from early amnion rupture: evidence for mechanical teratogenesis. J Pediatr. 1981;98:292-297.

18. Smith DW. Recognizable patterns of human deformation. Identification and management of mechanical effects on morphogenesis. Major Probl Clin Pediatr. 1981;21:1-151.
19. Luebke HJ, Reiser CA, Pauli RM. Fetal disruptions: assessment of frequency, heterogeneity, and embryologic mechanisms in a population referred to a community-based stillbirth assessment program. Am J Med Genet. 1990;36:56-72.

20. Portal P. La pratique des accouchements soutenue d'un grand nombre d'observations. Paris: G Martin; 1685.

21. Bhat BV, Pandey KK, Srinivasan S, Hebebulah S, Bupathy A. Intrauterine amputations associated with the amniotic band syndrome. Indian Pediatrics. 1991;28:188-191.

22. Yang SS, Levine AJ, Sanborn JR, Delp RA. Amniotic rupture, extraamniotic pregnancy, and vernix granulomata. Am J Surg Pathol. 1984;8:117-122.

23. Kino Y. Clinical and experimental studies of the congenital constriction band syndrome, with an emphasis on its etiology. J Bone Joint Surg Am. 1975;57:636-643.

24. Kennedy LA, Persaud TV. Pathogenesis of developmental defects induced in the rat by amniotic sac puncture. Acta Anat (Basel). 1977;97:23-35.

25. Werler MM, Bosco JL, Shapira SK. Maternal vasoactive exposures, amniotic bands, and terminal transverse limb defects. Birth Defects Res A Clin Mol Teratol. 2009;85:52-57.

26. Davies BR, Giménez-Scherer JA. Comparison of the amniotic band disruption complex with acardiac twins does not support its vascular origin. Fetal Pediatr Pathol. 2007;26:87-99.

27. McKenzie J. Amniotic bands. British Society for Developmental Biology, Symposium 2: The early development of mammals. Cambridge: University Press; 1975.

28. Lash JW. Normal embryology and teratogenesis: implications for pathological development from experiment embryology. Am J Obstet Gynecol. 1964;90(suppl):1193-1207.

29. Levy R, Lacombe D, Rougier Y, Camus E. Limb body wall complex and amniotic band sequence in sibs. Am J Med Genet A. 2007;143A:2682-2687.

30. Etches PC, Stewart AR, Ives EJ. Familial congenital amputations. J Pediatr. 1982;101:448-449.

31. Lubinsky M, Sujansky E, Sanger W, Salyards P, Severn C. Familial amniotic bands. Am J Med Genet. 1983;14:81-87.

32. Pauli RM, Lebovitz RM, Meyer RD. Familial recurrence of terminal transverse defects of the arm. Clin Genet. 1985;27:555-563.

33. Pagon RA. Amniotic adhesion malformations. Lancet. 1980;1(8179): 1198.

34. Herva R, Rapola J, Rosti J, Karlson H. Cluster of severe amniotic adhesion malformations in Finland. Lancet. 1980;1(8172)i:818-819.

35. Lockwood C, Ghidini A, Romero R, et al. Amniotic band syndrome in monozygotic twins: prenatal diagnosis and pathogenesis. Obstet Gynecol. 1988;71:1012-1015.

36. Russo R, D’Armiento M, Angrisani P, Vecchione R. Limb body wall complex: A critical review and a nosological proposal. Am J med Genet. 1993;47:893-900.

37. Potter EL. Pathology of the fetus and the Infant. Chicago: Year Book Medical Publishers: 1962. p. 374-378.
The Application of Clinical Genetics

\section{Publish your work in this journal}

The Application of Clinical Genetics is an international, peer-reviewed open access journal that welcomes laboratory and clinical findings in the field of human genetics. Specific topics include: Population genetics; Functional genetics; Natural history of genetic disease; Management of genetic disease; Mechanisms of genetic disease; Counselling and

\section{Dovepress}

ethical issues; Animal models; Pharmacogenetics; Prenatal diagnosis; Dysmorphology. The manuscript management system is completely online and includes a very quick and fair peer-review system, which is all easy to use. Visit http://www.dovepress.com/testimonials.php to read real quotes from published authors. 